\title{
Anomalous origin of the left pulmonary artery from the ascending aorta in two children with pulmonary atresia, sub-aortic ventricular septal defect and right-sided major aorto-pulmonary collateral arteries
}

\author{
L PEPETA, FF TAKAWIRA, PE ADAMS, NH NTSINJANA, BJ MITCHELL, AM CILLIERS
}

\begin{abstract}
We report two rare cases of an anomalous origin of the left pulmonary artery (AOLPA) from the ascending aorta, associated with pulmonary atresia, a ventricular septal defect and a left aortic arch. The cases are unusual because AOLPA is more commonly associated with a right aortic arch and it is more usual for the right pulmonary artery to originate anomalously from the ascending aorta. The pulmonary blood supply to the right lung in both patients was absent and provided instead by major aorto-pulmonary collateral arteries which were stenosed at multiple levels. The AOLPA in both patients originated from the postero-lateral aspect of the ascending aorta just distal to the sino-tubular junction. Only one patient showed the more common association of an unusual aortic arch branching pattern in the form of an anomalous right subclavian artery.

Neither patient was in heart failure and the chest X-ray in both revealed differential pulmonary perfusion with prominent vascularity of the left lung. Cardiac catheterisation showed systemic pressures within the anomalous left pulmonary artery. Karyotyping revealed normal chromosomes, and fluorescent in-situ hybridisation done in one patient was negative for chromosome 22 q11.2 microdeletion. Both patients have been managed conservatively.
\end{abstract}

Division of Paediatric Cardiology, Department of Paediatrics and Child Health, Dora Nginza Hospital, Port Elizabeth Hospital Complex, Walter Sisulu University, Port Elizabeth, South Africa

L PEPETA, FCPaed (SA), Cert Cardiol (SA), Lungile.Pepeta@gmail. com

Division of Paediatric Cardiology, Department of Paediatrics and Child Health, Chris Hani-Baragwanath Hospital, University of the Witwatersrand, Johannesburg, South Africa

AM CILLIERS, FCPaed (SA)

PE ADAMS, FCPaed (SA), Cert Cardiol (SA)

NH NTSINJANA, FCPaed (SA), Cert Cardiol (SA)

Division of Paediatric Cardiology, Department of Paediatrics and Child Health, Pretoria Academic Hospital, University of Pretoria, Pretoria, South Africa

FF TAKAWIRA, FCPaed (SA)

BJ MITCHELL, FCPaed (SA), Cert Cardiol (SA)
Keywords: pulmonary atresia with ventricular septal defect, anomalous origin of pulmonary artery, collateral arteries, pulmonary hypertension, branchial arches, $\mathrm{CATCH} 22$ syndrome

Submitted 23/3/10, accepted 31/8/10

Cardiovasc J Afr 2010; 21: October online publication www.cvja.co.za

DOI: CVJ-21.048

An anomalous origin of the pulmonary artery from the aorta (AOPA) is very rare, with the first case of this nature reported by Fraentzel in 1868. ${ }^{1}$ The incidence of anomalous left pulmonary artery from the aorta (AOLPA) was reported in one study to be around $17 \%,{ }^{1}$ with anomalous origin of the right pulmonary artery (AORPA) from the ascending aorta as the more common variant of AOPA, seen in about $83 \%$ of cases. Without surgery, the mortality in patients with AOPA is extremely high, reaching as high as $80 \% .^{2-5}$ This is due to severe, rapidly progressive pulmonary vascular disease and congestive cardiac failure. Both isolated AOLPA and that associated with other defects have been well described. ${ }^{1,6,7}$

The commonest associated congenital cardiac lesion is tetralogy of Fallot, which is seen in about $75 \%$ of cases. ${ }^{1}$ AOLPA is also associated with a right arch of the aorta in $63 \%$ of cases, and in about $38 \%$ of cases, an anomalous origin of the right subclavian artery from the descending aorta has been reported as well. ${ }^{1}$ Of note, both our cases had a left aortic arch and had no main and right pulmonary arteries, with the only source of blood supply to the right lung being partially stenosed major aorto-pulmonary collateral arteries (MAPCAs).

To the best of our knowledge, this series represents the first report in the literature of the anomalous origin of the left pulmonary artery arising from the aorta, associated with pulmonary atresia, with no central pulmonary arteries and MAPCAs supplying the whole of the right lung.

\section{Case 1}

This 10-month-old male patient was referred for assessment of a complex cyanotic heart lesion and a centrally positioned heart, namely mesocardia. Clinical assessment showed the patient to have central cyanosis, a loud single second heart sound, and 1/6 ejection systolic murmur over the left upper parasternal border. There were no abnormal facial features, no clubbing of the digits 


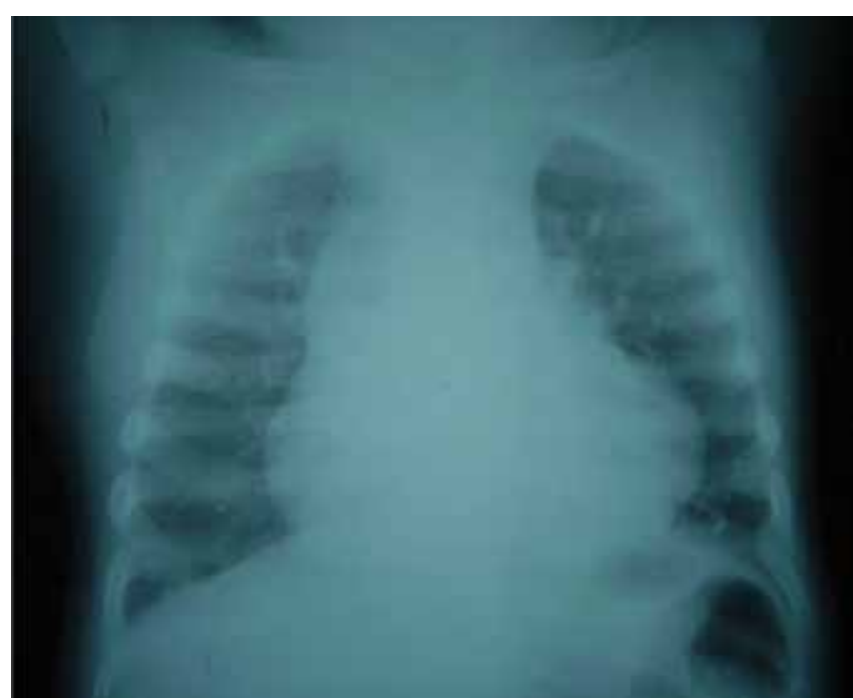

Fig. 1. Chest roentgenogram showing a boot-shaped heart, differential perfusion with increased perfusion to the left lung and reduced perfusion to the right lung.

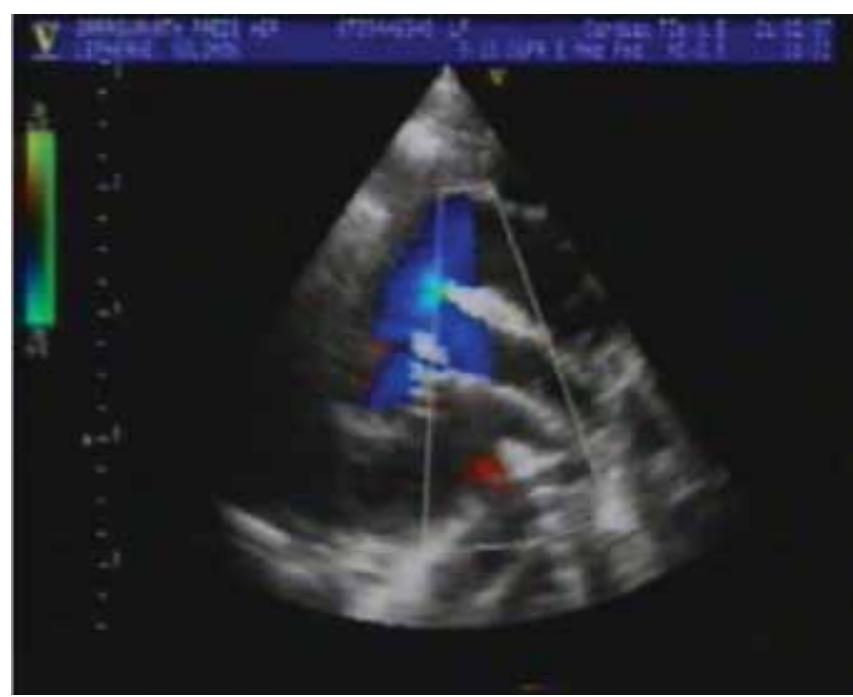

Fig. 2. Two-dimensional echocardiophic study with colour flow imaging showing the anomalous origin of the left pulmonary artery arising from the proximal ascending aorta.

or features of heart failure.

The chest X-ray showed a cardiothoracic index of $66 \%$, mesocardia, a left-sided aortic arch, a boot-shaped heart with right ventricular predominance and an absent pulmonary artery segment. Differential perfusion to the lungs was evident on the chest X-ray, showing prominent pulmonary vasculature on the left and reduced pulmonary vasculature on the right. Situs solitus was present (Fig. 1).

The electrocardiogram revealed right-axis deviation and right ventricular hypertrophy by voltage criteria. An echocardiographic assessment confirmed the presence of pulmonary atresia with a large mal-aligned peri-membranous (sub-aortic) ventricular septal defect, and an overriding aorta. A surprising finding was the anomalous origin of the left pulmonary artery from the left postero-lateral aspect of the ascending aorta, just above the sinotubular junction, and an aberrant right subclavian artery arising from the descending aorta distal to the left subclavian artery. In

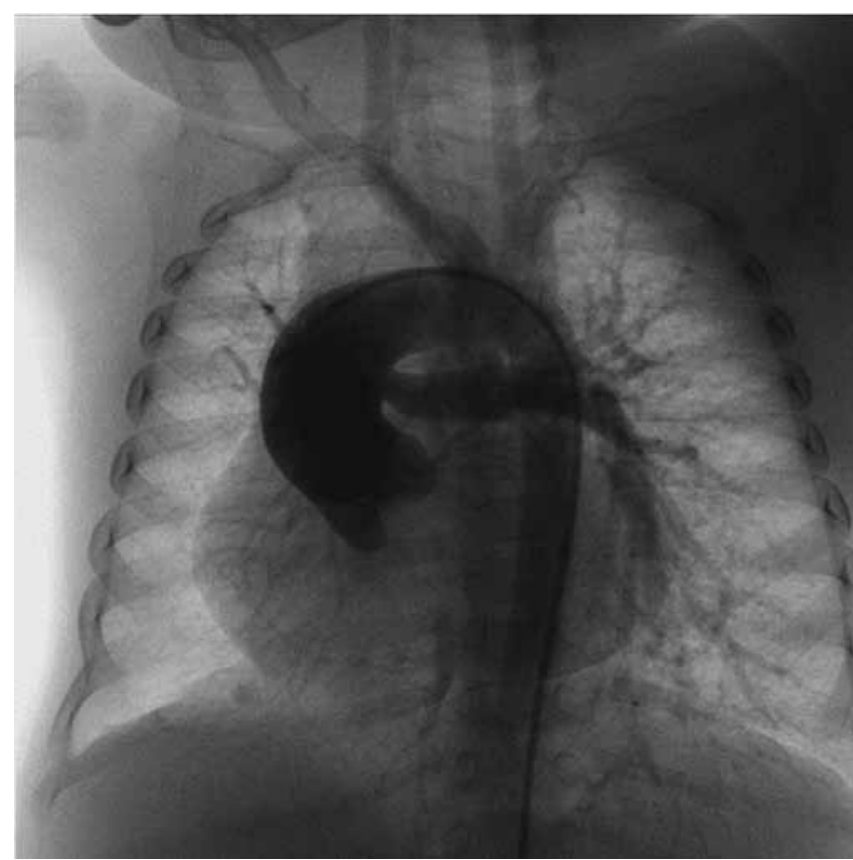

Fig. 3. Ascending aortogram in antero-posterior view showing a left aortic arch and the anomalous left pulmonary artery arising from the proximal ascending aorta.

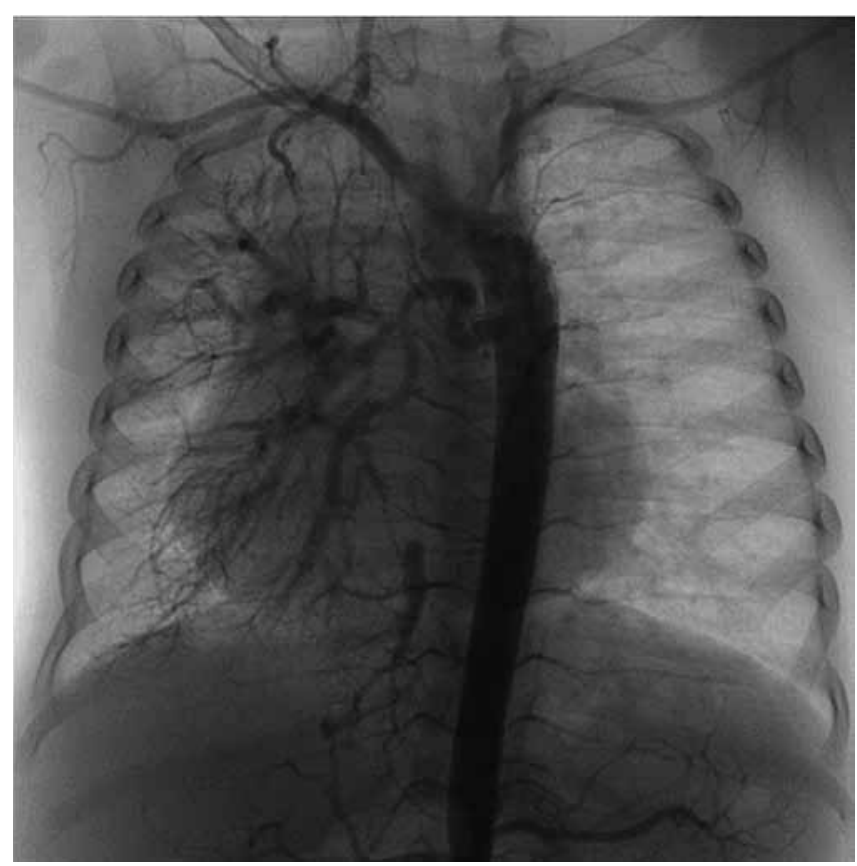

Fig. 4. Descending aortogram in antero-posterior view showing the aberrant right subclavian artery arising from the descending aorta distal to left subclavian artery. The major aorto-pulmonary collateral vessels to the right lung can also be seen.

addition, numerous major aorto-pulmonary collateral vessels were seen arising from the descending aorta, and the ascending aorta arched to the left (Fig. 2). The central pulmonary arteries were not visualised.

Angiography confirmed the above findings (Figs 3, 4). Of importance were the total absence of native pulmonary arterial vasculature and the presence of a bipartite right ventricle with an absent apical portion. Haemodynamic studies revealed very 
low systemic saturations of $79 \%$ and, as was expected, very high systolic pressures equalling that of the aortic pressures of $61 \mathrm{mmHg}$ in the aberrant left pulmonary artery. By contrast, the pressures measured within the major aorto-pulmonary collateral vessels which supplied all three lung segments on the right side were slightly elevated with a systolic pressure of $35 \mathrm{mmHg}$, and a mean of $19 \mathrm{mmHg}$. The patient was not offered any further treatment.

\section{Case 2}

The second case was a $6 \frac{1}{2} 2$-year-old female patient who presented with anomalous origin of the left pulmonary artery from the ascending aorta, pulmonary atresia with a ventricular septal defect (VSD), again associated with MAPCAs as the only supply to the right lung. She was diagnosed with this problem as a newborn baby. Unfortunately, she was lost to follow up and presented at $6 \frac{1}{2}$ years with worsening cyanosis and decreased effort tolerance. Clinically, she had no dysmorphism. She was cyanosed with pulse oximetry saturations of $85 \%$ at room air. There was associated digital clubbing. The precordium was bulging with a laterally displaced apex. The second heart sound was loud and single, and there was a $3 / 6$ ejection systolic murmur over the left upper parasternal border. There was no evidence of congestive cardiac failure.

On chest X-ray, the cardiothoracic ratio was slightly increased at $62 \%$, there was a left arch of the aorta, and the pulmonary artery segment was absent. Of note in this patient was differential perfusion with plethoric left lung fields, compared to the right.

The electrocardiogram revealed features of left atrial and left ventricular hypertrophy. On echocardiographic assessment, there was a large sub-aortic mal-aligned VSD with 50\% aortic override and bi-directional shunting across the VSD. The ventricles were balanced in size and the left atrium was dilated, with a left atrium:aortic index of 2.6. There was associated pulmonary atresia. The left pulmonary artery was noted to be arising from the ascending aorta just above the sino-tubular junction and both the main and the right pulmonary arteries were not seen.

At cardiac catheterisation, the systemic arterial saturations were low at $67 \%$, in keeping with a mixing situation. There were balanced ventricular pressures with systolics of $82 \mathrm{mmHg}$. As expected, the AOLPA pressures were systemic at $82 \mathrm{mmHg}$.

Angiography confirmed the echocardiographic findings of pulmonary atresia with a VSD, associated with an anomalous origin of the left pulmonary artery from the ascending aorta. There were no native pulmonary arteries supplying the right lung that were seen, and the only source of blood supply to the right lung was the partially stenosed MAPCAs arising from the descending thoracic aorta. This patient was conservatively managed as well.

\section{Discussion}

The presentation of a single pulmonary artery arising directly from the ascending aorta is very rare, and even less common is the entity of AOLPA. Besides the well-known association with tetralogy of Fallot, AOLPA is usually associated with a rightsided aortic arch and an absent patent ductus arteriosus (PDA). ${ }^{1}$ By contrast, our case study patients presented with a left arching aorta. ${ }^{1,6,8}$
A frequent association of AORPA is the CATCH 22 syndrome, ${ }^{7,9-14}$ which was not found in one of our cases, based on the absence of the 22q11 deletion anomaly following a fluorescent immuno-sorbent hybridisation (FISH) chromosomal analysis. The other patient was not tested for this chromosomal aberration.

Only one case has been reported in the literature, where AOLPA and tetralogy of Fallot with membranous pulmonary atresia were diagnosed. ${ }^{7}$ In this patient, there were welldeveloped central pulmonary arteries and the patient underwent successful complete surgical repair. The aetiology of AOPA is unclear, but one case of AORPA has been reported to be associated with foetal valproate syndrome. ${ }^{15}$

The pathogenesis of an anomalous pulmonary artery originating from the aorta is said to be related to an abnormality in the development of the aortic or branchial arches. ${ }^{1,6}$ The failure of resorption of the fifth branchial arch and presence of the sixth brachial arch usually lead to the anomalous origin of the right pulmonary artery from the aorta. ${ }^{1,6}$ By contrast, the anomalous origin of the left pulmonary artery from the aorta is reported to be due to developmental absence of the fifth and sixth branchial arches. Abnormalities of the branchial or aortic arches are associated with neural crest-cell aberrations and therefore may be associated with the CATCH 22 syndrome..$^{79-14}$ Precursors of the trunco-aortic sac are mainly of mesodermal origin, ${ }^{16}$ therefore AOPA is unlikely to be associated with the trunco-aortic sac abnormalities. ${ }^{1}$

The origin of AOPA anatomically is usually very proximal, arising from the ascending aorta just distal to the aortic sinus..$^{1,2,7,17}$ Other origins of the pulmonary arteries, such as at the base of the innominate artery, from a patent ductus arteriosus, or from the thoracic aorta distal to the subclavian artery have been described and can be labelled as 'distal types of AOPA'. They are not the same entity that is described in this case study. ${ }^{18}$

The clinical presentation is that of a significant left-to-right shunt with early and rapidly progressive pulmonary hypertension, with or without right-sided heart failure., ${ }^{3,14,19,20}$ The pulmonary vascular disease affects both lungs, and may be seen as early as three months of age. ${ }^{20}$ The mechanism by which both lungs are affected involves neurogenic crossover from the involved lung to affect the protected lung, thereby producing reflex vasoconstriction in the protected lung., ${ }^{3,720}$ Diastolic run-off due to shunting of blood away from the aorta into the aberrant pulmonary artery may affect coronary perfusion and result in left ventricular dysfunction. ${ }^{14}$

The diagnosis of AOPA can be easily achieved by careful echocardiography. ${ }^{7,10,21-24}$ Other imaging modalities such as cineangiography,,$^{21,22,25}$ or magnetic resonance angiography have also been utilised. ${ }^{26}$

Due to the rapid development of irreversible pulmonary vascular disease in infancy and associated high mortality in the patients presenting with AOPA, re-implantation of the pulmonary artery is an operation that needs to be performed within the first year of life. .,3,8,10,27 $^{2}$

\section{Conclusion}

Anomalous origin of the pulmonary arteries from the ascending aorta, and more specifically the left pulmonary artery is a rare entity, which can be diagnosed with readily available imaging modalities. The management is surgical re-implantation of the 
anomalous vessel, but may provide a management challenge if complicated by pulmonary hypertension or other associations such as pulmonary atresia with collateral vessels.

\section{References}

1. Kutsche LM, Van Mierop LHS. Anomalous origin of a pulmonary artery from the ascending aorta: Associated anomalies and pathogenesis. Am J Cardiol 1988; 61:850-856.

2. Penkoske PA, Castaneda AR, Fyler DC, Van Praagh R. Origin of pulmonary artery branch from the ascending aorta. Primary surgical repair in infancy. J Thorac Cardiovasc Surg 1983; 85: 537-545.

3. Benatar A, Kinsley RH, Milner S, Dansky R, Hummel DA, Levin SE. Surgical correction for one pulmonary artery arising from the aorta report of five cases. Int J Cardiol 1987; 16: 249-255.

4. Fontana GP, Spach MS, Effmann EL, Sabiston DC, Jr. Origin of the right pulmonary artery from the ascending aorta. Ann Surg 1997; 206 102-113.

5. Kaene JF, Maltz D, Bernhard WF, Corwin RD, Nadas AS. Anomalous origin of one pulmonary artery from the ascending aorta: Diagnostic, physiological and surgical considerations. Circulation 1974; 50: 588-594.

6. Aru GM, English WP, Gaymes CH, Heath BJ. Origin of the left pulmonary artery from the aorta: Embryologic considerations. Ann Thorac Surg 2001; 71: 1008-1010.

7. Prifti E, Bonacchi M, Murzi B, Crucean A, Bernabei M, Luisi VS, et al. Anomalous origin of the left pulmonary artery from the aorta. Our experience and literature review. Heart Vessels 2003; 18: 79-84.

8. Abu-Sulaiman RM, Hashmi A, McCrindle BW, Williams WG, Freedom RM. Anomalous origin of one pulmonary artery from the ascending aorta: 36 years' experience from one centre. Cardiol Young 1998; 8(4): 449-454.

9. Johnson MC, Watson MS, Strauss AW, Spray TL. Anomalous origin of the right pulmonary artery from the aorta and CATCH 22 syndrome. Ann Thorac Surg 1995; 60: 681-683.

10. Fong LV, Anderson RH, Siewers RD, Trento A, Park SC. Anomalous origin of one pulmonary artery from the ascending aorta: a review of echocardiographic, catheter, and morphological features. Br Heart $J$ 1989; 62: 389-395.

11. Saliba Z, le Bidois J, Sidi D, Kachener J, Bonnet D. Prenatal detection of a tetralogy of fallot with origin of the left pulmonary artery from the ascending aorta in a familial 22q11 microdeletion. Prenat Diagn 1999; 19: $260-262$.

12. Sett SS, Sandor GG, Mawson JB. Interrupted right aortic arch and origin of the left pulmonary artery from the aorta in DiGeorge syndrome. Cardiol Young 2001; 11: 676-679.

13. Dodo H, Alejos JC, Perloff JK, Laks H, Drinkwater DC, Williams RG Anomalous origin of the left main pulmonary artery from the ascend- ing aorta associated with DiGeorge syndrome. Am J Cardiol 1995; 75: 1294-1295.

14. Peng EWK, Shanmugam G, Macarthur KJD, Pollock JCS. Ascending aortic origin of a branch pulmonary artery-surgical management and long-term outcome. Euro J Cardio-Thorac Surg 2004; 26: 762-766.

15. Mo CN, Ladusans EJ. Anomalous right pulmonary artery origins in association with fetal valproate syndrome. J Med Genet 1999; 36: 83-84.

16. Bergwerrf M, Verberne ME, DeRuiter MC, Poelmann RE, Gittenbergerde-Groot AC. Neural crest cell contribution to the developing circulatory system. Implications for vascular morphology? Circ Res 1998; 82: 221-231.

17. Nakamura Y, Yasui H, Kado H, Yonenaga K, Shiokawa Y, Tokunaga $\mathrm{S}$. Anomalous origin of the right pulmonary artery from the ascending aorta. Ann Thorac Surg 1991; 52: 1285-1291.

18. Talaat A, Sayed HM, Terzaky AK, Sharaf M, Hamed MA. Anomalous origin of the right pulmonary artery from the descending thoracoabdominal aorta (report of three cases). J Egypt Med Assoc 1974; 57: 328-343.

19. Kirkpatrick SE, Girod DA, King H. Aortic origin of the right pulmonary artery. Surgical repair without a graft. Circulation 1967; 36: 777-782.

20. Yamaki S, Suzuki Y, Ishizawa S, Kagawa Y, Horiuchi T, Sato T. Isolated aortic origin of right pulmonary artery. Report of a case with special reference to pulmonary vascular disease in the left and right lung. Chest $1983 ; \mathbf{8 3}$ : 575-578.

21. Mittal PK, Agarwal SK, Ghosh PK. Isolated anomalous origin of left pulmonary artery from the ascending aorta in an adult. $J$ Thorac Cardiovasc Surg 1993; 106: 1220-1223.

22. Lo RNS, Mok CK, Leung MP, Lau KC, Cheung DLC. Cross sectional and pulsed doppler echocardiographic features of anomalous origin of right pulmonary artery from the ascending aorta. Am J Cardiol 1987; 60: 921-924.

23. Santos MA, Azevedo VMP. Anomalous origin of one pulmonary artery from the ascending aorta. Surgical repair resolving pulmonary arterial hypertension. Arq Bras Cardiol 2004; 83: 503-507.

24. Duncan WJ, Freedom RM, Olley PM, Rowe RD. Two-dimensional echocardiographic identification of hemitruncus: anomalous origin of one pulmonary artery from ascending aorta with the other pulmonary artery arising normally from the right ventricle. Am Heart J 1981; 102: 892-896.

25. Griffiths SP, Levine OR, Anderson DH. Aortic origin of the righ pulmonary artery. Circulation 1962; 25: 73-84.

26. Katayama H, Shimizu T, Tanaka Y, Narabayashi I, Tamai H. Threedimensional magnetic resonance angiography of vascular lesions in children. Heart Vessels 2000; 15: 1-6.

27. Armer RM, Schumacker HB, Klatte EC. Origin of the right pulmonary artery from the ascending aorta: report of a surgical corrected case. Circulation 1961; 24: 662-668. 